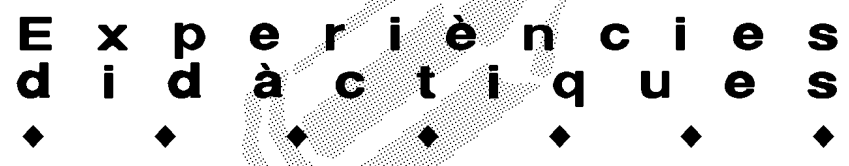

\section{LA LUDOÈTNIA DE SOS RACISME: UN RECURS PER TREBALLAR LA INTERCULTURALITAT A PARTIR DEL JOC I LA JOGUINA}

\author{
Biel Pubill i Soler. Mestre d'Educació Física a l'IES de Flix
}

\begin{abstract}
Justificació
El present article vindica l'important paper que té el joc com a mitjà per ajudar a la integració de l'alumnat 0 grups socials amb problemes d'adaptació, aportant tot un seguit de recursos basats en l'aplicació de jocs de tot el món. A més es presenten idees i reflexions que facilitaran al mestre el disseny i desenvolupament d'una unitat de programació que ben bé podríem titular Coneguem formes de jugar d'altres països o cultures i que tindria com a eix vertebrador el joc i la joguina.

La idea, per tant, és la d'aportar materials que ajudin el mestre o formador a educar a través dels jocs i les joguines que trobem en diferents països i continents. Construint els jocs i contrastant informació diversa es buscarà complir la funció cultural que del joc es desprèn: ensenyar a través del joc que en el món hi ha gran diversitat de cultures. A partir d'aquí, aconseguir un intercanvi cultural i educar en la interculturalitat.
\end{abstract}

\section{Introducció i precedents}

Segons Toni Costes (1997), "Els jocs no són patrimoni de ningú, no s'ha de parlar de jocs d'una comarca o una altra", o jocs d'un lloc determinat, "sinó de jocs jugats en una comarca" o zona concreta, "perquè en el joc el protagonista és el jugador, procedeixi d'on procedeixi".

La majoria de jocs, així com dels objectes materials d'aquests, no són exclusius d'un indret concret sinó que són presents i habituals en moltes comunitats i cultures dels cinc continents. Què és el que canvia, doncs? Sovint són molt poques les diferències, i aquestes vénen donades per les característiques geogràfiques i climàtiques dels diferents indrets. Aquests condicionants donen lloc a relleu i vegetació diferenciada que particularitza algunes accions de joc 0 alguns materials per a la construcció de joguines.

Reconèixer aquesta idea comporta l'acceptació, el respecte i la tolerància a la diferència cultural. I aquest és un pilar bàsic a tenir en compte en el camp de l'educació, i més avui que l'increment, als centres docents, d'alumnes d'origen divers (de nord d'Àfrica, de països eslaus, de sud Amèrica, d'ètnia gitana...) és una constant. Cal que disposem d'eines i materials que facin possible la integració d'aquests i el respecte mutu envers la pluralitat cultural.

El joc en pot ser una eina molt important. En aquest sentit, possibilitar la presentació de jocs i joguines d'altres països ha de suposar un enriquiment per al grup, un interès major per part de tots per saber com es viu en altres indrets, per saber com es juga als altres llocs, per conèixer quines destreses empra cadascú... Quan es facilita al nou vingut un marc on poder esdevenir protagonista, se l'està ajudant a ser reconegut pel grup i se l'està integrant.

Ningú discutirà que el joc així viscut prepara per a la immersió social, permet ser solidari i receptiu a les propostes dels companys i empeny a aprendre en un marc distès.

Convençuts d'aquestes reflexions, des del departament d'Educació Física de l'IES Flix, de la Ribera d'Ebre, portem ja tres anys treballant en aquesta línia. Així hem dissenyat el crèdit variable Coneguem formes de jugar d'altres països o cultures, que s'ofereix als alumnes de $2 \mathrm{n}$ d'ESO, i hem elaborat tot un seguit d'unitats de programació que tenen com a eix vertebrador la ludoètnia de SOS Racisme.

\section{La ludoètnia de SOS Racisme}

La ludoètnia és un taller creat per l'ONG SOS Racisme, amb la intenció no sols que els alumnes coneguin nous jocs de països diversos sinó, principalment, d'apropar les diferents cultures a través del joc, fomentant així actituds de solidaritat, interès, respecte i tolerància cap aquestes. Es pretén així prevenir actituds de racisme i intolerància que avui, malauradament, són notícia, fent del joc una reflexió encaminada a acceptar la diversitat cultural com a motiu d'enriquiment.

El taller així pensat està format per una trentena de plafons que expliquen jocs de diferents cultures i el seu origen, els contextualitzen i els situen en el temps. La part principal de la mostra la constitueix un centenar de jocs d'arreu del món, la majoria de taula, que són expli- 


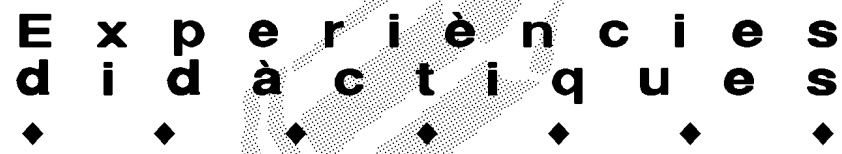

cats per un monitor de SOS Racisme. Entre aquests trobem jocs exòtics com el Joc reial d'Ur (Mesopotàmia, $2600 \mathrm{aC}$ ), el Senet(Egipte, $1350 \mathrm{aC}$ ), la Tabula (Roma), l'Escala o la Serp (Índia), el Parxís (Índia, s.V aC), Envoltar la llebre i l'Alquerque (recollits per Alfons X en la seva obra Un recull o llibre de jocs, l'any 1283), l'Assalt (Anglaterra, s. XIX), diferents variants de la família dels Mancala: l'Awale, el Wari... (d'Àfrica), el Tres en ratlla (Egipte, $1400 \mathrm{aC}$ ), el Dominó (Xina, segle XVII)... Però també molts jocs que coneixem com a tradicionals i que ja eren citats als Diàlegs de Buda (s. V $\mathrm{aC}$ ), com el de la Xarranca -un dels més antics que coneixem és el que hi ha gravat a les pedres del Fòrum de Roma-; els Ossets (pídols, poms, astràgals...); la Baldufa-Virgili l'esmenta a l'Eneida-; el io-io conegut a l'antiga Grècia...

La ludoètnia ens permet fer entendre a l'alumnat que cap joc és exclusiu d'un lloc ni té unes normes que no es poden alterar. S'adonen que les característiques d'espai, de clima, de relleu, de vegetació, d'economia, del nombre de jugadors que volen participar, de la diferència d'edats d'aquests, de les destreses generals del grup... són condicionants a l'hora de jugar, ara i abans. En el moment que s'adonen d'això es desperta en el noi l'interès per altres cultures, i el seu coneixement ha de conduir-lo a respectar-les i a ser més tolerant i solidari.

\section{Algunes orientacions per a la intervenció pedagògica}

La següent seqüència és orientativa, i té la pretensió d'ajudar a l'hora de dissenyar unes sessions tipus que condueixin a fomentar el treball en la diversitat:

- Presentar les joguines i els jocs o formes jugades (amb suport visual en uns casos, amb l'explicació o la manipulació o la pràctica directa en d'altres).

- Creació de joguines o elements de joc.

- Buscar relacions amb els jocs que ells coneixen.

- Invitar els nois a buscar variants als jocs apresos posant-los en pràctica per tal que se'ls facin més seus i els interioritzin -això afavorirà el diàleg i el consens.

- Incentivar la recerca d'informació relacionada amb

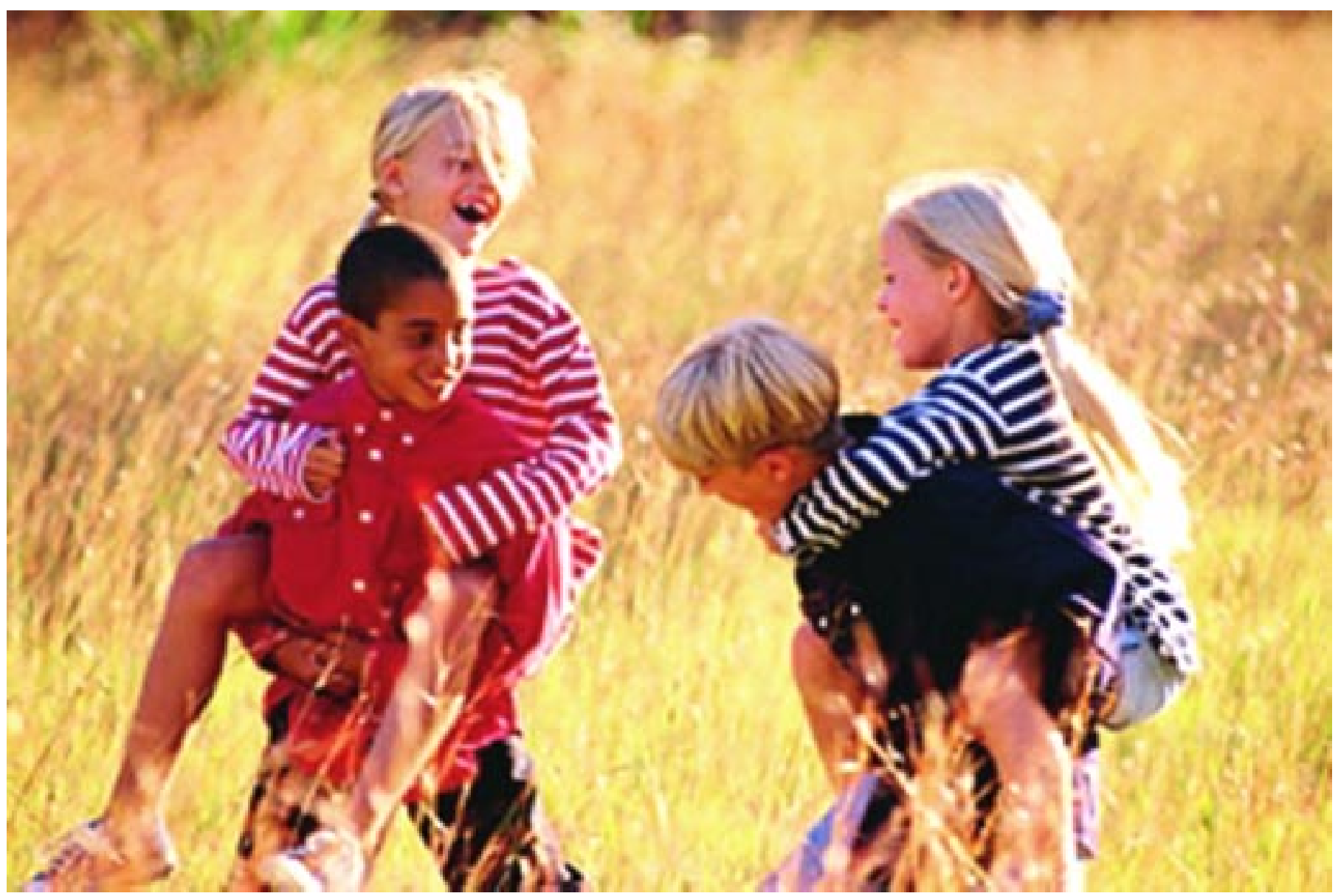




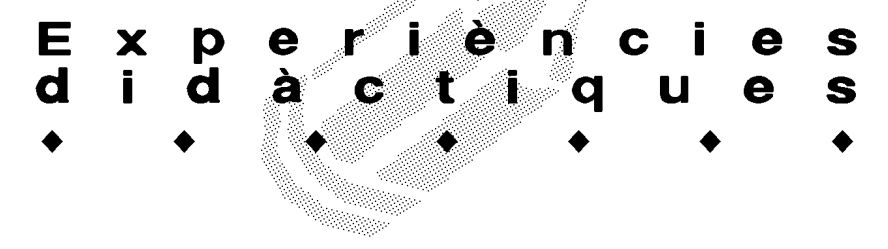

els jocs i joguines presentades a través dels seus familiars i amics i, com no, d'altres fonts de consulta (bibliogràfiques, cibernètiques...).

- Convertir-los en protagonistes directes dels jocs, fent-los passar per nadius de països llunyans, que explicaran a nens d'altres cursos de la pròpia o d'altres escoles jocs de diferents cultures.

- Participar en un projecte comú amb escoles de diferents països, intercanviant jocs i, si és possible, establint fòrums i xats de conversa.

- Autoavaluar i valorar cadascuna de les activitats proposades.

Fóra bo treballar el crèdit interdisciplinàriament amb les àrees de Tecnologia i d'Educació Visual i Plàstica, i disposar d'un taller o espai prou ampli i habilitat per tal de poder construir moltes de les joguines o elements de joc que aniran sorgint.

Per fi, penso que és essencial l'elaboració d'un recull-dossier de les activitats dutes a terme al llarg de la unitat de programació. Serà a través d'aquest recull que l'alumne podrà recordar jocs, expressar el seu estat anímic en cada cas fent-ne una valoració, ser creatiu explicitant noves formes de joc inventades per ell, anotar aquelles records que els seus parents li donaran, etc.

\section{Criteris i activitats per a l'avaluació}

Proposem una avaluació formativa. És per això que tindrem molta cura a observar la participació de l'alumnat en les diferents activitats, veure com interaccionen entre ells, comprovar el grau d'integració en el grup i anotar les actituds d'ajuda, solidaritat i respecte.

A més, però, enregistrarem informació sobre:

- Les capacitats expressives i sensorials: sensibilitat, imaginació i creativitat a l'hora de jugar i crear objectes de joc.

- Les capacitats d'autonomia personal: iniciativa, presa de decisions, planificació.
- Les capacitats psicomotrius: agilitat, precisió, destresa.

- Les actituds davant l'aprenentatge: constància i regularitat en el treball, interès per superar-se, motivació.

Els models de taula 1, d'observació, i taula 2, de valoració, poden ser recursos útils per a l'avaluació.

\section{Conclusions}

Fixem-nos que tota l'estona hem parlant d'integració! Integració del nen i de la nena en un nou grup classe aportant els materials que ha trobat tafanejant en el record dels seus predecessors. Integració, alhora, i major cohesió no sols amb el grup sinó també amb la cèl-lula familiar donat que sorgeix el diàleg entre pares i fills. Hem de parlar d'una integració afegida, la dels iaios. En trobar un tema de conversa comú esdevenen protagonistes en els relats que fan als seus néts. És important, doncs, entendre aquesta activitat com facilitadora de la comunicació intergeneracional.

Al llarg de la unitat s'adonaran que l'origen dels jocs és divers, i que sovint es juga de formes semblants a llocs molt allunyats geogràficament. El fet de distingir diferents maneres d'anomenar el mateix objecte material que permet multitud de jocs esdevé una riquesa afegida en el procés d'aprenentatge, les aportacions d'alumnes procedents d'altres indrets i cultures fan que ens trobem en un clar camí cap al pluralisme, el respecte i el reconeixement de la diversitat cultural.

A tall de conclusió, diria que el joc intercultural i les joguines esdevenen una important eina d'integració per als docents i educadors, monitors i moviments associatius donat que faciliten la participació intergeneracional, potencien la tolerància $\mathrm{i}$ el respecte pel coneixement d'altres cultures, la cooperació entre els participants, la solidaritat pels resultats obtinguts en un clima que ha de ser distès i poc competitiu, l'enriquiment cultural resultat

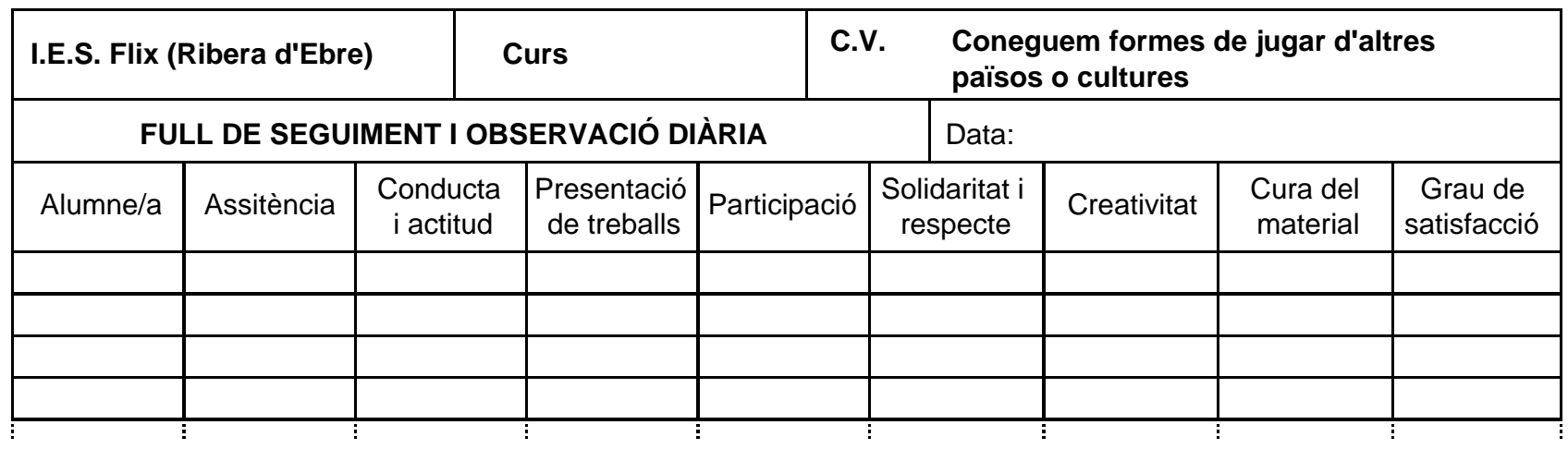

Taula 1. Model d'observació del treball de l'alumne 


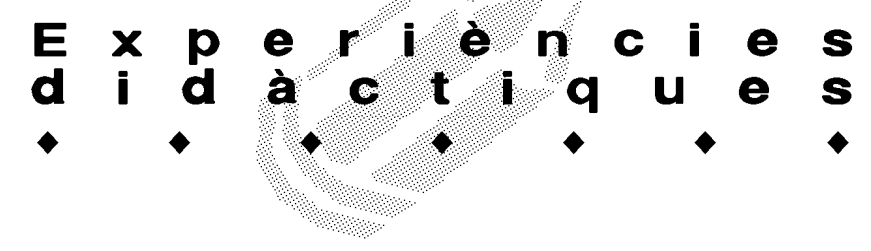

de les aportacions de cadascú i, per últim, afavoreixen la cohesió i sentit de pertinença a un grup. Vertebrant la unitat didàctica a partir de la ludoètnia podem treballar la interculturalitat. Amb tot plegat pensem que des d'una actuació lúdica aprofundim en el coneixement de la diversitat cultural fent de la diferència l'enriquiment personal dels joves.

\section{Fonts de consulta i altres recursos} joc

Empreses i entitats que treballen a partir de la joguina i el

ARTIJOC (Gestió, béns i serveis per la cultura, el lleure i l'ensenyament), C/ Enric Borràs, 15. 08329 Teià (El Maresme). Ofereix tallers de Jocs d'arreu del món i lloguer de la Ludoteca Intercultural Tulundang (de pagament).

CAMP D'APRENENTATGE DE TARRAGONA (Complex Educatiu de Tarragona. Autovia de Salou s/n. 43006, Tarragona). Han dissenyat el dossier Juguem com jugaven les nenes i els nens de Tàrraco, que va acompanyat d'una maleta de jocs amb reproduccions de joguines i jocs de l'època romana. Molt interessant. Servei gratuït.

CARRUTXA (Centre de documentació de la cultura popular). Plaça Mercadal, 9. Reus. Per fer qualsevol consulta sobre aspectes relacionats amb el joc i la joguina tradicional.

CENTRE DE PROMOCIÓ DE LA CULTURA POPULAR I TRADICIONAL. C/ Portal de Santa Madrona 6-8. 08001 Barcelona Tel. 934125640 . Per fer qualsevol consulta sobre aspectes relacionats amb el joc i la joguina tradicional.

INTERMÓN. Roger de Llúria, 15. 08010 Barcelona. Tel. 934820 700. Mostra de joguines africanes. Exposició de joguines d'Àfrica (de pagament).

MUSEU NACIONAL ARQUEOLÒGIC DE TARRAGONA. Tel 977236209 / 977251 515. Interessant el dossier i el taller Vine a conèixer la cultura romana. Entre les vitrines del museu n'hi ha una dedicada a entreteniments i joguines dels nens romans -podreu contemplar la famosa nina d'ivori-. Entrada al museu pagant.
MUSEU ETNOLÒGIC DE BARCELONA. Passeig de Sta. Madrona s/n. Parc de Montjuïc. 08038 Barcelona. Tel. 934 246807 / 934246 402. Organitzen periòdicament tallers sobre jocs de diferents països (de pagament).

MUSEU DE JUEGOS TRADICIONALES de Campo (Osca) C/ Pallerez. Tel. 974550 136. Museu fonamental per a tots aquells interessats en jocs tradicionals d'Espanya, des d'un punt de vista no sols lúdic sinó també des de l'antropologia, contextualitzant aspectes socials i culturals (entrada gratuïta).

MUSEU DEL MONTSIÀ. C/ Gran Capità, 34. 43870 Amposta. Tel. 977702 954. Disposen d'una brillant exposició itinerant (de pagament) sobre joguines tradicionals de la zona de l'Ebre. Hi ha editat tot un seguit de dossiers per als alumnes i disposen de servei de monitors.

REBALLUGA. Apartat de correus 11, 43791 Ascó. Tel. 977405 785. Mostra i Taller de construcció de joguines senzilles de l'Associació Cultural Lo Llaüt d'Ascó, especial per a centres cívics, esplais o tallers a escoles.

SOS RACISME: LUDOĖTNIA "100 jocs de cultures"(servei gratuït que compta amb un monitor). Cal posar-se en contacte amb els Serveis de Benestar Social de la Generalitat de Catalunya o bé, directament amb l'ONG SOS Racisme.

\section{Bibliografia sobre jocs ilo esports del món}

ALLUÉ, J. Ma․ El gran llibre dels jocs. Edit. Parramón. Barcelona. 1998.

AMADES, J. Auca dels jocs de la mainada. Edit. Alta Fulla. Barcelona. 1984.

ANDRÉS MARTIN, F. Juegos y deportes autóctonos. Edit. Centro de Cultura Tradicional de la Diputación de Salamanca. 1990.

BEAUVIALA, A.C. Jeux de société traditionnels. Histoire et règle de 100 jeux. Editions Bonneton. París. 1997.

CASTELLOTE, R. M. Juegos de los indios norteamericanos para jugar en la naturaleza. Miraguano ediciones. Madrid. 1986.

COMAS COMA, O. Agenda 2001. Jocs del món. Edicions Hipòtesi, S.L./Triangle Postals S.L. Barcelona. 2000.

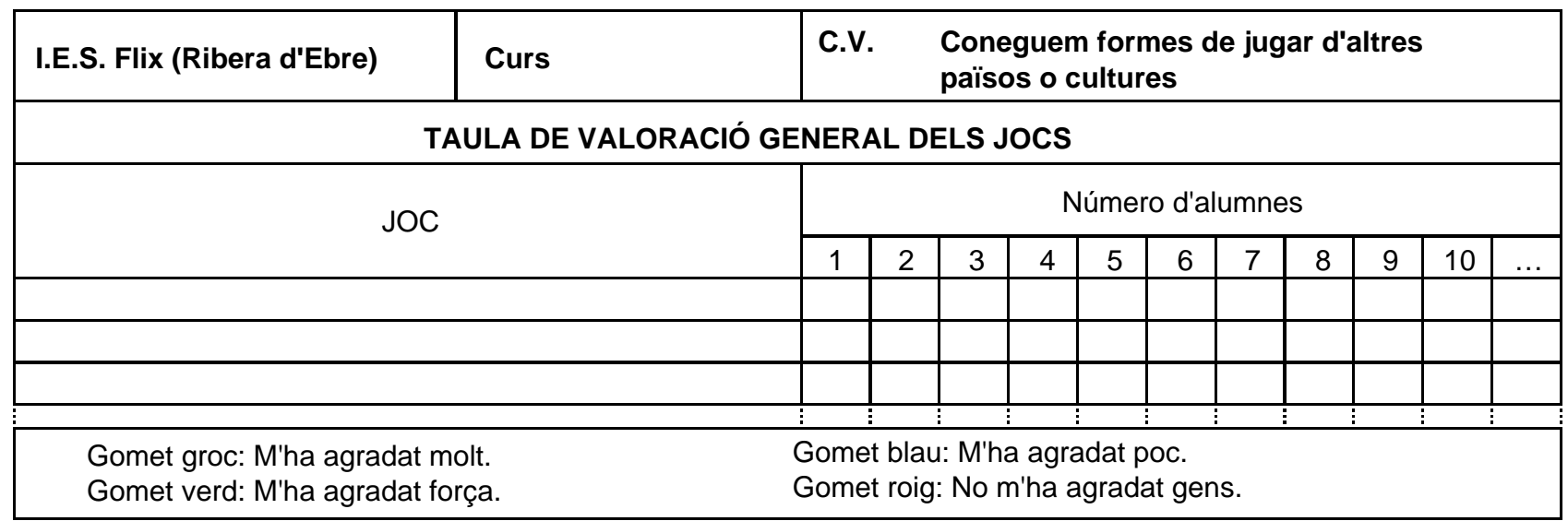

Taula 2. Model d'avaluació del treball de l'alumne 


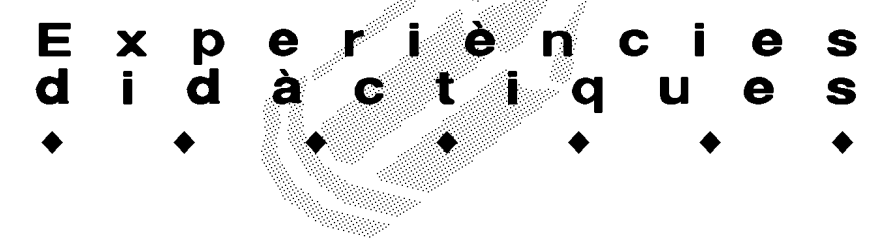

CORREDOR-MATHEOS, J. La joguina a Catalunya. Edicions 62, S. A. Barcelona. 1981.

CORREDOR-MATHEOS, J. El juguete en España. Edit. Espasa Calpe, S.A., Madrid. 1999.

COSTAFREDA CASTILLO, A. Jocs i entreteniments populars (d'Artesa de Lleida). Col-lecció La Femosa. Edit. Pagès Editors. Lleida. 1997.

COSTES RODRÍGUEZ, A. "Emborrapà". Jocs de carrer jugats a Amposta. Edita Ajuntament d'Amposta. 1997.

CREUS BONCOMPTE, R., i VILADOT PUIG, J. Jocs dels infants d'Agramunt. 5 è col-leccionable de la revista SIÓ. Edita revista SIÓ. Agramunt. 1996.

DESCOMPS, D. Jouets d'autrefois. Edit. Ostal del llibre de l'Institut d'Estudis Occitans. Orlhac. 1994.

DESCOMPS, D. Jouets de toujours. Edit. Ostal del libre de l'Institut d'Estudis Occitans. Orlhac. 1997.

HERMAN, P. Le livre d'or des Jouets en bois. Edit. Glénat. Brusel.les. 1992.

KANDERT, J. Les jouets dans le monde. Edit. Librairie Gründ. Paris. 1994.

LAVEGA BURGUÉS, i P. i OLASO CLIMENT, S. 1000 juegos y deportes populares y tradicionales. La tradición jugada. Edit. Paidotribo. Barcelona. 1999.

MAESTRO GUERRERO, F. Del tajo a la replaceta. Juegos y divertimentos del Aragón rural. Ediciones 94. Zaragoza. 1996.

MARIN, I., i PARDO, O. El jugar de l'Amades (1) i (2). Edicions EI Mèdol. Tarragona. 1996.

MORENO PALOS, C. Aspectos recreativos de los juegos $y$ deportes tradicionales en España. Gymnos editorial.

MUÑOZ DE LA MATA, N. Jeux du monde. UNICEF i Edit. La Nacelle. 1996.

ORLICK, T. Libres para cooperar, libres para crear. Edit. Paidotribo. Barcelona. 1995.

POU, A. Jocs populars. Biblioteca "Les illes d'or", núm. 128. Edit. Moll. Mallorca. 1989.

QUERALT, Ma C. Els joguets dels iaios-quaderns de treball pels mestres i alumnes per a l'exposició que organitza el Museu del Montsià-. Amposta. 1992.

RICE, C, i RICE, M. L 'histoire des enfants du monde. Edit. Larousse-Bordas. 1997.

SANZ, I. Juegos populares de Castilla y León. Col.lecció Nueva Castilla, Núm. 4. Castilla Ediciones. Valladolid. 1994.

VIOLANT SIMORRA, R. La joguina tradicional. Edit. Alta Fulla. Barcelona. 1996.

AAVV. Jocs i tallers interculturals. Col-lecció Lleure. Edita CAE, formació i serveis sòcio-culturals. 1998.

AAVV. Juguem com jugaven les nenes i els nens de Tàrraco. Edita Camp d'Aprenentatge de la ciutat de Tarragona. Tarragona. 2000.

AAVV. Todos los juegos del mundo. Enciclopedias Planeta. Edit. Planeta. Barcelona. 2000.

Articles i Revistes

COLORS, Toys / Juguetes núm. 29 (desembre 98 - gener 99). Editorial Offices, Benetton Group SpA Villa Minelli, Itàlia.
PUBILL SOLER, G. Els jocs dels nostres iaios. Vehicle per a la integració. "Guix», 265 (2000) 47-52.

SADA, P. Divertim-nos amb els romans. Generalitat de Catalunya. Museu Nacional Arqueològic de Tarragona i CÒDOL. Serveis educatius. 2000.

\section{Fonts cibernètiques}

http://www.ddgi.es/bibpuig/jocs.htm. Jocs del Món: la ludoteca de la Biblioteca Comtat de Cerdanya.

http://www.ahs.uwaterloo.ca/ museum/index.html. Història i manera de jugar de molt jocs (arxiu de jocs de la Universitat de Waterloo a Ontario, Canadà).

http://www.gamecabinet.com/deeperDrawers/ Traditional.html. Jocs tradicionals desenvolupats pels víkings, els romans i durant l'època medieval.

http://www.regia.org/games.htm. Jocs de taulell dels víkings i l'edat mitjana anglosaxona.

http://www.xtec.es/-rbadia/jocs.htm. Recull de jocs del món.

http://www.mastersgames.com/misc/invalidpage.htm. Regles i la història de nombrosos jocs de taulell.

http://www.maclachlans.org/games.html. Jocs tradicionals d'Escòcia.

http://www.japanlink.co.jp/ka/cplafr.htm. Jocs tradicionals del Japó.

http://www.meadev.gov.in/sports/tr games/ indigenous.htm. Jocs de l'Índia.

http://www.rena.e12.ve/deporte/depjuego.html. Jocs de Veneçuela.

http://www.quepasa.cl/revista/1380/7.html. Jocs de Xile. http://www.emirates.org/traditions/games/. Jocs dels Emirats Àrabs (en anglès), diferenciats per sexes.

http://www.un-mongolia.mn/ger-mag/ger-mon5.htm. Jocs de Mongòlia.

http://www.gio.gov.tw/info/culture/culture3.html. Jocs sobre la República de Xina (diàbolo, baldufes...).

http://www.kidlink.org/spanish/kidproj-spanish/juegos/proy ecto.htm. Adreça per intentar un intercanvi de jocs amb nens del Perú.

http://roble.pntic.mec.es/ fblanc1/entorno/juegos.htm. Permet contactar amb una escola d'Àvila interessada a fer intercanvi de jocs tradicionals.

http://www.flight-toys.com/index.htm. Informació sobre jocs o esports de llançaments (boomerang, fones...).

http://www.drac.com/pers/viktor/wari/. Jocs de mancala. http://www.fln.vcu.edu/murphy-judy/sports/fletcher-lacross e.html. Explicació del joc de Lacrosse (propi dels nadius del nord d'Amèrica).

http://www.cult.gva.es/museus/M00089/noframes e.htm. Museu Valencià de Joguets a IBI.

http://wwwmalraux.culture.fr/. Museu de Joguines de Poissy, a França. 